\title{
Effectiveness of a combined obesity prevention program in South Korea for children from low-income families that included primary caregiver participation
}

\author{
Namhee Park ${ }^{1}$, Mihae $\mathrm{Im}^{2}$ \\ ${ }^{1}$ Associate Professor, Institute of Health Science, College of Nursing, Inje University, Busan; ${ }^{2}$ Assistant Professor, Department of Nursing, Choonhae College of \\ Health Scineces, Ulsan, Korea
}

Purpose: Obesity among children from low-income families is becoming a social problem. The aim of this study was to evaluate the effectiveness of an obesity prevention program that included physical activity, nutrition education, behavioral modification, and primary caregiver participation components among children from low-income families. Methods: The study analyzed a nonequivalent control group using a pretest-posttest design. A total of 77 children were recruited from six community childcare centers using purposive sampling. For the intervention group $(n=40)$, the pretest was administered before the combined intervention program involving the participants' primary caregivers was conducted for 8 weeks. The posttest was conducted immediately after the program and again four weeks after the program. Results: Flexibility $(\mathrm{F}=4.64, p=.020)$, muscular endurance $(\mathrm{F}=11.22, p<.001)$, nutritional knowledge scores $(\mathrm{F}=4.79, p=.010)$, body image satisfaction scores $(\mathrm{F}=4.74, p=.012)$, and self-esteem scores $(\mathrm{F}=3.81, p=.029)$ showed significant differences and interactions between group and time for the intervention and control groups. Conclusion: Strategies to actively engage the primary caregivers of low-income families in children's obesity programs are needed. Obesity prevention programs for children based on the program in this study should be routinely developed, and continuing attention should be given to children from low-income families.

Key words: Children; Obesity; Community participation; Parents

\author{
Corresponding author \\ Mihae Im \\ Department of Nursing, Choonhae \\ College of Health Scineces, Daehak-gil 9, \\ Ungchon-myeon, Ulju-gun, Ulsan 44965, \\ Korea \\ TEL: +82-52-270-0216 \\ FAX: +82-52-270-0189 \\ E-MAIL: mihae1219@gmail.com
}

Received Mar 12, 2021

Revised Apr 7, 2021

Accepted May 21, 2021

\section{INTRO DUCTION}

An association has been found in children between being from low-income families and overweight/obese status [1]. In the United States, the obesity rate of children aged 2-19 years old from families in the lowest income range was $18.9 \%$, whereas the obesity rate of children from families in the highest income range was $10.9 \%$ [1]. In South Korea, according to a survey of third and sixth-grade elementary school students $(n=4,327)$, while the obesity rate of children from high-income families was $3.5 \%$, it was $6.1 \%$ for children from low-income families nearly twice that of high-income families [2]. Children with unmanaged obesity are more likely to develop chronic diseases in adulthood than non-obese children [3]. Managing chronic diseases often entails an economic burden and thereby contributes to a vicious cycle of poverty in which both chronic diseases and poverty are exacerbated [4]. Children from low-income families are less likely to participate in physical activity programs and maintain healthy diets due to their low economic status [1,3]. In addition, both parents from low-income families tend to have to work and thus eat out frequently and eat prepared foods that are easy to cook [5]. Lowincome children have also been found to be more likely to eat meals or snacks while watching TV than children of other classes, which is one of the reasons for their increased risk of obesity [3]. Therefore, overweight/obese children from lowincome families require support.

There are three main approaches for managing obesity in children. The first approach is to conduct exercise interventions to enhance children's physical activity, the second approach is nutrition education to improve children's eating habits, and the last approach is behavior modification for im- 
proving children's overall lifestyles [6]. These approaches can be implemented alone or together to design obesity management programs for children. A previous meta-analysis found that childhood obesity was most effectively managed when physical activity and nutrition education were implemented together [7]. Bleich et al. [8] also examined the effects of community-based programs for obese children in a meta-analysis and found that these programs were most effective when they included both physical activity and nutrition education. Moreover, conducting multiple simultaneous intervention programs that include behavior modification has also been recommended, since cultivating a healthy lifestyle and self-management is essential for managing child obesity in the long term [9].

An important consideration for obesity prevention in children is their surrounding environment. Existing health programs mainly deal with internal factors associated with health issues, such as a lack of knowledge and improvement of one's lifestyle. However, it is necessary to consider the various environments that children inhabit when developing intervention programs intended to change children's behavior [10]. Within these environments, parents have the greatest impact on children's lifestyles [5]. In the home environment, parents have the greatest influence on the nutritional and behavioral habits of children. For example, if parents are knowledgeable about nutrition, children tend to consume more fiber, low-fat foods, vegetables, and fruits [11]. On the contrary, if parents are inactive and frequently watch TV at home, children naturally tend to imitate those living patterns [3].

In addition, parents can encourage their children to form healthy eating habits and lifestyle habits, as well as to actively participate in programs [5]. Parents can help their children shape their eating habits by providing them with healthy meals [1]. In addition, parents can support their children by encouraging them to participate in obesity management programs and monitoring their children's eating habits and exercise levels with appropriate reinforcement so that their children maintain healthy lifestyles $[1,5]$.

However, very few obesity intervention programs that involve parents or primary caregivers have been conducted in South Korea [10]. Although Kim et al. [12] examined newsletters and text messages sent to parents about managing their children's obesity, this method is still limited when it comes to actively encouraging parents' participation and helping parents to monitor their children's obesity. Park et al. [10] found that only $17.7 \%$ of programs conducted from 1996 to 2015 in South Korea incorporated participation by caregivers. Although primary caregivers are aware of the importance of their role in managing obesity in their children, there are still only a few programs that reflect this awareness in South Korea. Therefore, in this study, we aimed to develop a com- bined obesity prevention program for children from low-income families that includes primary caregiver participation and examine its effects on body mass index (BMI), physical strength, nutritional intake, nutritional knowledge, body image satisfaction, and self-esteem. The following hypotheses were investigated:

Hypothesis 1. There will be significant differences in BMI between the groups and at different times in the intervention group and control group.

Hypothesis 2. There will be significant differences in physical strength (flexibility, muscular endurance, agility) between the groups and at different times in the intervention group and control group.

Hypothesis 3 . There will be significant differences in nutritional intake (fruit, vegetable, and dairy intake) between the groups and at different times in the intervention group and control group.

Hypothesis 4. There will be significant differences in nutritional knowledge scores between the groups and at different times in the intervention group and control group.

Hypothesis 5. There will be significant differences in body image satisfaction scores between the groups and at different times in the intervention group and control group.

Hypothesis 6. There will be significant differences in self-esteem scores between the groups and at different times in the intervention group and control group.

\section{METHODS}

Ethics statement: This study was approved by the institutional review board of Inje University (No. 2018-07-002). Informed consent was obtained from the participants.

\section{Study Design}

This is a quasi-experimental study that used a nonequivalent control group pretest-posttest design to examine the effectiveness of a combined obesity prevention program aimed at children from low-income families that incorporated primary caregiver participation.

\section{Setting and Samples}

Community childcare centers (CCCs) in South Korea provide after-school care services for children from low-income families. CCCs are available to children from low-income families based on Korean household income standards as well as to other children who require community protection and support such as children with disabilities and single-parent or 
grandparent-led families. According to data on the economic status of children who use CCCs, only $7.6 \%$ of children came from families whose income exceeded $100 \%$ of the median, $38.2 \%$ of children were from families with an income of $50 \%$ to $85 \%$ of the medium, and $25.3 \%$ of children were from families with an income of less than $50 \%$ of the median [13]. Considering these characteristics, CCC users were selected as a target group since CCCs are a key environment for low-income families in South Korea. First, we met with the directors of CCCs and explained the objective and methods of this study. As a result, six centers that agreed to participate were selected for this study. To avoid the effect of interactions during the course of the study, the six centers were divided into three intervention centers, where the program would be conducted, and three control centers based on geographic proximity using purposive sampling. The specific selection criteria for participants in this study were as follows. First, the participants had to be elementary school students enrolled in a CCC. Second, children with chronic diseases, such as diabetes and hypertension, were not included. Third, the children and primary caregivers had to agree to participate in the study. Fourth, the children had to be from low-income families according to South Korean household income standards. Fifth, the children had to be able to answer a self-reported questionnaire.

The required sample size was calculated using $G^{*}$ Power version 3.1.2. In total, 70 participants were needed for this study with an effect size of .23, which was determined based on a previous meta-analysis of a childhood obesity program in Korea [6], a significance level of .05, a statistical power of .90 , a nonsphericity correction $\varepsilon$ of .50 , two groups, three measurements, and two-way repeated-measured analysis. Accounting for an expected attrition rate of $20 \%, 42$ students were recruited for the intervention group and the control group. In the control group, two students dropped out of this study due to moving elsewhere, and three students did not complete the follow-up test 1 month after the study had ended (11.9\% dropout rate). In the intervention group, two students did not complete the follow-up test 1 month after the study had ended ( $4.8 \%$ dropout rate) (Figure 1). As a result, data from 40 participants in the intervention group and 37 participants in the control group were included in the final analyses.

\section{Ethical Considerations}

This study was approved by the institutional review board (No.2018-07-002). A pamphlet was prepared to explain the objectives and procedures of the study to children and primary caregivers. It also explained that participants could withdraw from the study at any time without repercussions and that in- formation about participants would remain confidential and would not be used for purposes other than research. A researcher then called the primary caregivers via phone to again explain the purpose and procedure of the study and obtained verbal consent. Written consent forms were then sent to the primary caregivers who had given verbal consent, and they were signed by the primary caregivers and given to the children to bring to the CCC. Verbal consent was obtained from the children before both data collection and the start of the program.

To avoid any stigma from being classified as a low-income family, we avoided using descriptions that could add to that stigma such as "low-income families" or "single-parent families" in all educational materials, and the educators also fully recognized this problem before conducting research.

\section{Measurements}

Pretest data collection took place at the introductory session (the day before the program), and posttest data collection took place at the concluding session (the day after the program). One month after the end of the program, the research assistants made an appointment to visit the CCC to conduct data collection. The same research assistants performing data collection were blinded with regard to the group assignment.

\section{1) Body mass index}

BMI was measured using an Inbody analyzer (Inbody 3.0, Biospace co., Seoul, Korea), an automatic measuring tool, in kilograms per meter squared. To minimize errors, the same qualified researcher measured the BMI of all children at the same time before meals while they wore light clothes and no shoes.

\section{2) Physical strength evaluation}

The Physical Activity Promotion System (PAPS) [14] has been a commonly used method for measuring children's physical strength in elementary schools in South Korea since 2009. Using the specific manual for the PAPS [14], strength evaluations were taken by the one trained researcher who had majored in physical education.

\section{(1) Flexibility}

Flexibility was measured using trunk flexion, which is a test that measures the degree to which subjects can bend their body in a sitting position with their legs straight. The subjects maintained a bent posture for more than 2 seconds to ensure that their knees did not rise, and the distance on the ruler at the stop point of both fingers was measured in centimeters. 


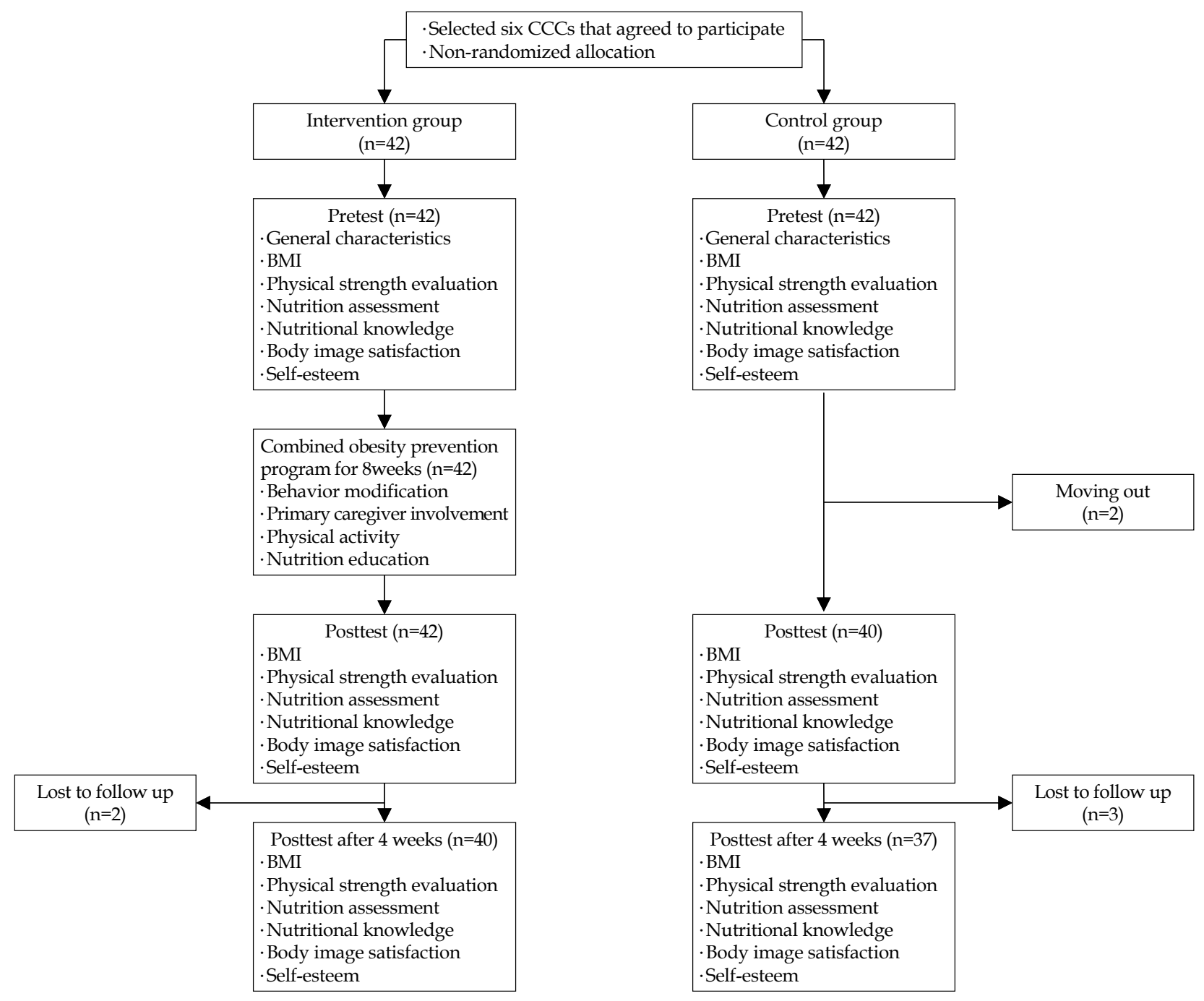

Figure 1. Flow diagram for participants. BMI, body mass index; CCC, child care center.

(2) Muscular endurance

Muscular endurance was measured using sit-ups. Children were asked to lie down with their fingers interlocked behind their heads and then raise their upper body when a researcher said the word "start," touching both elbows to both knees, then returning to their original lying position. The fingers should not separate during the exercise, and the researcher recorded the number of repetitions the subject could perform within 1 minute.

\section{(3) Agility}

Agility was measured using a standing long jump. A measurement was recorded at the point where the subject's two feet landed, taking care not to fall over the line. After two repetitions, with distances measured to $0.1 \mathrm{~cm}$, the higher of the two measurements was selected.

\section{3) Nutritional assessment}

Based on the Fourth National Health Plan Obesity Index [15], the nutritional status of the children was assessed according to their weekly and daily intake of fruits, vegetables, and dairy products.

\section{4) Nutritional knowledge}

Based on the Fourth National Health Plan Obesity Index [15], five nutrition-related survey questions were answered by the children. Questions were asked about the recommended number of vegetables one should consume per day, what nutrients were in fruits and vegetables, which foods were rich in calcium, which foods were good as snacks, and which foods to avoid so as not to gain weight. The answers to all the questions were averaged out of 100 points.

\section{5) Body image satisfaction}


A body image satisfaction scale was developed by Franzoi and Shields [16] to measure satisfaction with each part of the body, and Shin [17] redesigned the scale specifically for children in elementary school. The scale consisted of 24 questions, with answers measured on a 5-point Likert scale (1=very dissatisfied to $5=$ very satisfied). A higher score indicated a more positive body image. Cronbach's was .91 in Shin's study [17] and .96 to .97 in this study.

\section{6) Self-esteem}

The Self-Perception Profile developed by Harter [18], which was translated and modified by Lee and So [19], was used in this study. This instrument included 27 items which subjects rated using a 4-point Likert scale (1=strongly disagree to $4=$ strongly agree). A higher score indicated higher self-esteem. Cronbach's was .87 in Lee and So's study [19] and .93 to .96 in this study.

\section{Combined Obesity Prevention Program}

In this study, a combined obesity prevention program that included components on nutrition, physical activity, behavior modification management, and primary caregiver participation was developed by organizing a research team consisting of experts in related fields and reviewing previous studies and literature related to child obesity management. Subsequently, three external consultants from the research team who specialized in physical education, nutrition, and pediatric nursing were invited to enhance the validity of the program's curriculum. After that, the program's applicability to the children targeted in this study was evaluated by asking CCC managers, employees, and social workers to assess the difficulty and scope of the program. In addition, the role of each researcher and research assistant was classified, and the same curriculum was taught repeatedly to increase the reliability and validity of the study. During the course of the program, progress was confirmed through weekly meetings with the program operators and center instructors. The program was conducted for 8 weeks from July 30 to September 20, 2018, and consisted of four interventions. After the 8-week program ended, the same program was provided to the control group. An outline of the program is shown in Table 1.

\section{1) Behavior modification}

The behavior modification component was conducted by a researcher who specialized in pediatric nursing with experience in childhood obesity management. The goal of the behavior modification component was to analyze factors that led to obesity and encourage the children to adopt a healthy lifestyle, under the assumption that obesity is caused by over- eating and lack of activity, based on the five phases of behavior modification among obese children shown in a study by Saelens et al. [20].

\section{(1) Self-monitoring}

Using a self-behavioral diary, the children maintained and managed healthy lifestyles on their own to further understand what habits, behaviors, and attitudes led to their obesity. The children monitored 20 healthy lifestyle habits each day and checked them daily with their primary caregivers and teachers in the center.

(2) Goal setting

Based on the children's obesity measurements and questionnaire answers, one researcher in charge of operating the program spoke with each child to establish specific goals for individualized eating habits, lifestyles, and weight loss that each child could achieve.

\section{(3) Problem-solving}

The factors that prevented children from achieving their goals were identified and discussed with children and primary caregivers to resolve the impediment using telephone counseling.

(4) Stimulus control

In order to control the children's environment, the center provided physical activity and nutrition education classes. At home, primary caregivers allowed the children to control their environment.

\section{(5) Rewarding}

Small gifts were provided to the children who achieved their weekly goals and faithfully completed their self-behavioral diaries. After the completion of the program, one child was rewarded for the most regular participation, and a certificate was given to all of the students who participated.

\section{2) Primary caregiver involvement}

Primary caregivers participated in behavioral modification and cooking classes, based on the understanding that children for whom ideal weight, healthy eating, and physical activity are modeled by their primary caregivers have a significantly lower chance of becoming obese when they reach adulthood $[12,20]$. The subjects' current eating habits, lifestyles, weight, and obesity levels were provided and possible solutions to the problems were discussed during recurring telephone interviews that took place at least once per week. Primary caregivers were also provided with weekly educational materials that could be used at home to help the children achieve their 
Table 1. Overview of the Program

\begin{tabular}{|c|c|c|}
\hline \multicolumn{2}{|l|}{ Program } & Main contents \\
\hline \multicolumn{2}{|c|}{ Introductory session (120 minutes) } & $\begin{array}{l}\text { - Distribution and retrieval of the applications for the program } \\
\text { - Program guide for primary caregivers of participating children } \\
\text { - Pre-program survey of measurement variables } \\
\text { - Final goal and weekly goal setting after individual questionnaire analysis }\end{array}$ \\
\hline \multirow[t]{3}{*}{ Session 1} & PA 1 (50 min) & Understanding and practicing boxing \\
\hline & PA $2(50 \mathrm{~min})$ & $\cdot$ Muscle strengthening exercise 1 \\
\hline & NE $1(50 \mathrm{~min})$ & - Balanced diet (class): Food balance wheel, balanced eating \\
\hline \multirow[t]{4}{*}{ Session 2} & PA 3 (50 min) & - Basic postures in boxing (hook, switch) \\
\hline & PA 4 (50 min) & - Muscle strengthening exercise 2 \\
\hline & NE $2(40 \mathrm{~min})$ & - Balanced diet (practice): Practicing a balanced meal (tortilla), one serving size for one person \\
\hline & CC 1 (90 min) & $\begin{array}{l}\text { Cooking class with primary caregiver } \\
\text { - Try a balanced meal: Tofu sushi }\end{array}$ \\
\hline \multirow[t]{3}{*}{ Session 3} & PA 5 (50 min) & - Basic postures in boxing (weaving) \\
\hline & PA 6 (50 min) & $\cdot$ Muscle strengthening exercise 3 \\
\hline & NE 3 (50 $\mathrm{min})$ & $\begin{array}{l}\text { - Healthy snacks (class): Learn about healthy snacks, compare healthy snacks with unhealthy snacks } \\
\text { (learn about your sugar intake), choose healthy snacks }\end{array}$ \\
\hline \multirow[t]{4}{*}{ Session 4} & PA 7 (50 min) & - Basic postures in boxing (ducking) \\
\hline & PA 8 (50 min) & - Muscle strengthening exercise 4 \\
\hline & NE 4 (50 min) & $\begin{array}{l}\text { - Healthy snacks (practice): Making healthy snacks (rice cake skewers), committing to eating healthy } \\
\text { snacks }\end{array}$ \\
\hline & CC 2 (90 min) & $\begin{array}{l}\text { Cooking class with primary caregiver } \\
\cdot \text { Healthy snacks: Fruit punch }\end{array}$ \\
\hline \multirow[t]{3}{*}{ Session 5} & PA 9 (50 min) & $\cdot$ Music boxing using boxing training, section 1 \\
\hline & PA 10 (50 min) & - Muscle strengthening exercise 5 \\
\hline & NE 5 (50 min) & - Understanding food label (class): How to read food labels, how to use food labels \\
\hline \multirow[t]{4}{*}{ Session 6} & PA 11 (50 min) & - Music boxing using boxing training, section 2 \\
\hline & PA 12 (50 min) & $\cdot$ Muscle strengthening exercise 6 \\
\hline & NE $6(50 \mathrm{~min})$ & - Cooking with nutrients in food balance wheel: Making spring rolls \\
\hline & CC 3 (90 $\mathrm{min})$ & $\begin{array}{l}\text { - Cooking class with primary caregiver } \\
\text { - No picky eating: Sandwiches }\end{array}$ \\
\hline \multirow[t]{3}{*}{ Session 7} & PA 13 (50 min) & - Music boxing using boxing training, section 3 \\
\hline & PA 14 (50 min) & $\cdot$ Muscle strengthening exercise 7 \\
\hline & NE 7 (50 min) & - Food diary: How to write in and use it \\
\hline \multirow[t]{4}{*}{ Session 8} & PA 15 (50 min) & - Music boxing using boxing training, section 4 \\
\hline & PA 16 (50 min) & - Muscle strengthening exercise 8 \\
\hline & NE $8(50 \mathrm{~min})$ & - Cooking with nutrients in the food balance wheel (practice): Making kimchi-vegetable rice balls \\
\hline & CC 4 (90 min) & $\begin{array}{l}\text { Cooking class with primary caregiver } \\
.5 \text { major nutrients: Kimbap }\end{array}$ \\
\hline Session $1-8$ & $\begin{array}{l}\text { Behavior } \\
\text { modification } \\
(30 \mathrm{~min})\end{array}$ & $\begin{array}{l}\text { - Inspection of food and exercise diary } \\
\text { - Set weekly objectives and evaluate } \\
\text { - Establishing a goal attainment plan } \\
\text { - Issue education materials about obesity management at home, weight, BMI, and children's weekly } \\
\text { goals } \\
\text { - Encourage management of child obesity at home through telephone counseling once per week with } \\
\text { primary caregiver }\end{array}$ \\
\hline \multicolumn{2}{|c|}{ Concluding session (120 min) } & $\begin{array}{l}\text { - Training on the importance of follow-up guidance and sustainability management } \\
\cdot \text { Post-program survey of measurement variables } \\
\cdot \text { Evaluation of program, compensation, and completion ceremony }\end{array}$ \\
\hline \multicolumn{2}{|c|}{ Post-program survey (1 month later) } & $\begin{array}{l}\text { - Tracking children's participation in the program } \\
\text { - Post-program survey of measurement variables after one month }\end{array}$ \\
\hline
\end{tabular}

BMI, body mass index; CC, cooking class; NE, nutrition education; PA, physical activity. 
goals. Additionally, caregivers were informed of the children's progress in the program to encourage cooperation at home and the children's participation. Primary caregivers also participated in the cooking class so that they could practice a healthy diet together with their children.

\section{3) Physical activity}

To attract the interest of the children, we conducted a physical activity that combined music boxing and muscle strengthening exercise. Music boxing was conducted once a week for 50 minutes. A professional instructor provided training regarding boxing's basic movements and then trained the children in those movements along to K-pop music. Musclestrengthening exercises were conducted once a week for 50 minutes, with classes being conducted by a professional weight trainer. Push-ups (against the wall, kneeling on the floor), squats, a tug game, and resistance exercise using body weights or resistance bands were included to increase muscle strength and bone health. The exercises mentioned were adapted into games with group activities to keep the children interested.

\section{4) Nutrition education}

Nutrition education was conducted by a professional instructor for 50 minutes each week. To increase the effectiveness of the program, we conducted a cooking class with children based on what we learned during the previous week. After learning about the five nutrients included on the Korean "food balance wheel", children made tortillas to help teach them about eating a balanced meal. Having learned to choose healthy snacks, the children made rice cake skewers that were low in salt, sugar, and fat. In addition, in order to encourage the children to increase their consumption of vegetables, spring rolls and rice balls were made using vegetables that children did not typically eat enough of. In addition, a cooking class with children and their caregivers was offered to help children become familiar with the nutritional properties of food ingredients and reduce their resistance to foods by participating in fun cooking activities such as making tofu sushi, fruit punch, sandwiches, and kimbap. By conducting cooking classes with caregivers every 2 weeks, we tried to foster family ties and closeness while also promoting good eating habits.

\section{Data Analysis}

Data analysis was conducted using SPSS version 25.0 (IBM Corp., Armonk, NY, USA). Homogeneity of variances was determined by conducting the Levene test. Homogeneity testing for general characteristics and outcome variables was performed using the independent t-test and $x^{2}$ test. Repeated- measures analysis of variance was used to compare the difference between dependent variables. The Greenhouse- Geisser correction was used when the variables did not fulfill the sphericity assumption. Comparison of the changing variables between groups was performed using the t-test.

\section{RESULTS}

\section{Homogeneity of Variance Test for Outcome Variables}

The equality of variance of dependent variables such as BMI ( $\mathrm{F}=0.01, p=.939)$, flexibility ( $\mathrm{F}=0.08, p=.773)$, muscular endurance $(\mathrm{F}=3.66, p=.060)$, agility $(\mathrm{F}=0.10, p=.758)$, fruit intake $(\mathrm{F}=0.01, p=.946)$, vegetable intake $(\mathrm{F}=0.06, p=.807)$, dairy intake $(\mathrm{F}=0.06, p=.803)$, nutritional knowledge scores $(\mathrm{F}=3.24$, $p=.076)$, body image satisfaction scores $(\mathrm{F}=3.65, p=.060)$, and self-esteem scores $(\mathrm{F}=3.40, p=.069)$ were confirmed using the Levene test.

\section{Homogeneity Test for General Characteristics and Outcome Variables}

There were no differences in the general characteristics and outcome variables between the two groups ( $p>.050$ ) (Table 2).

\section{Hypothesis Testing}

\section{1) Hypothesis 1}

Regarding BMI, there were no statistically significant differences between the groups $(\mathrm{F}=3.56, p=.063)$ or interaction between group and time ( $\mathrm{F}=1.11, p=.318)$. There was a significant difference across the time points $(\mathrm{F}=16.50, p<.001)$ (Table 3). Therefore, hypothesis 1 was rejected.

\section{2) Hypothesis 2}

In terms of flexibility, there were no statistically significant differences between the groups $(\mathrm{F}=0.11, p=.739)$ or across the time points $(\mathrm{F}=1.47, p=.235)$. There was a statistically significant interaction between group and time ( $\mathrm{F}=4.64, p=.020)$. The flexibility of the intervention group increased by $1.63 \pm$ $4.31 \mathrm{~cm} 4$ weeks after the intervention $(\mathrm{t}=2.34, p=.002)$ (Figure 2-A, Table 3).

In addition, for muscular endurance, there was no significant difference between the groups $(\mathrm{F}=3.09, p=.083)$. There were statistically significant differences across time points $(\mathrm{F}=14.02, p<.001)$ and an interaction between group and time $(\mathrm{F}=11.22, p<.001)$. The muscular endurance of the intervention group increased by $13.83 \pm 17.99$ number of repetition per minute immediately after the intervention $(\mathrm{t}=3.23, p=.002)$ and by $18.18 \pm 22.68$ number of repetition per minute 4 weeks 
after the intervention $(t=4.03, p<.001)$ (Figure 2-B, Table 3).

Regarding agility, there were no statistically significant differences between the groups $(\mathrm{F}=1.33, p=.253)$, differences across time points $(\mathrm{F}=0.90, p=.383)$, or interaction between group and time $(\mathrm{F}=2.84, p=.078)$ (Table 3$)$. The intervention group showed improved flexibility and muscular endurance, but not agility. Therefore, hypothesis 2 was partially supported.

\section{3) Hypothesis 3}

For fruit intake, there were no statistically significant differences between the groups $(\mathrm{F}=0.27, p=.605)$, differences across time points $(\mathrm{F}=1.30, p=.276)$, or interaction between group and time $(\mathrm{F}=0.32, p=.730)$ (Table 3$)$.
For vegetable intake, there were no statistically significant differences between the groups $(\mathrm{F}=1.30, p=.258)$, differences across time points $(\mathrm{F}=2.73, p=.081)$, or interaction between group and time $(\mathrm{F}=0.34, p=.664)$ (Table 3$)$.

For dairy intake, there were statistically significant differences between the groups $(\mathrm{F}=5.10, p=.013)$ and across time points $(\mathrm{F}=5.05, p=.013)$. However, the interaction between group and time was not statistically significant $(\mathrm{F}=0.24, p=.734)$ (Table 3). Therefore, hypothesis 3 was rejected.

\section{4) Hypothesis 4}

For the nutritional knowledge scores of the children, there were statistically significant differences across time points $(\mathrm{F}=23.69, p<.001)$ and a significant interaction between group

Table 2. Homogeneity Test for General Characteristics and Outcome Variables $(N=77)$

\begin{tabular}{|c|c|c|c|c|c|c|}
\hline \multirow[t]{2}{*}{ Variables } & \multirow[t]{2}{*}{ Characteristics } & \multirow[t]{2}{*}{ Categories } & $\begin{array}{l}\text { Intervention } \\
\quad(n=40)\end{array}$ & $\begin{array}{l}\text { Control } \\
(n=37)\end{array}$ & \multirow[t]{2}{*}{$\mathrm{t}$} & \multirow[t]{2}{*}{$p$} \\
\hline & & & $\mathrm{n}(\%)$ or $\mathrm{M} \pm \mathrm{SD}$ & $\mathrm{n}(\%)$ or $\mathrm{M} \pm \mathrm{SD}$ & & \\
\hline \multirow{7}{*}{$\begin{array}{l}\text { Children's } \\
\text { general } \\
\text { characteristics }\end{array}$} & Age (year) & & $10.15 \pm 1.17$ & $10.54 \pm 1.19$ & 1.45 & .151 \\
\hline & Sex & Male & $14(35.0)$ & $15(40.5)$ & 0.25 & .616 \\
\hline & & Female & $26(65.0)$ & $22(59.5)$ & & \\
\hline & Weight status & Low weight & $5(12.5)$ & $2(5.4)$ & 3.25 & .355 \\
\hline & & Normal & $29(72.5)$ & $27(73.0)$ & & \\
\hline & & Overweight & $6(15.0)$ & $6(16.2)$ & & \\
\hline & & Obese & - & $2(5.4)$ & & \\
\hline \multirow{13}{*}{$\begin{array}{l}\text { Primary } \\
\text { caregiver's } \\
\text { general } \\
\text { characteristics }\end{array}$} & Relationship & Father & $6(15.0)$ & $8(21.6)$ & 4.26 & .119 \\
\hline & & Mother & $33(82.5)$ & $24(64.9)$ & & \\
\hline & & Grandparent & $1(2.5)$ & 5 (13.5) & & \\
\hline & Age (year) & & $41.38 \pm 6.78$ & $44.70 \pm 9.04$ & 1.84 & .070 \\
\hline & BMI $\left(\mathrm{kg} / \mathrm{m}^{2}\right)$ & & $22.30 \pm 3.38$ & $22.92 \pm 3.17$ & 0.83 & .412 \\
\hline & Weight status & Low weight & $5(12.5)$ & $2(5.4)$ & 1.56 & .668 \\
\hline & & Normal & $25(62.5)$ & $25(67.6)$ & & \\
\hline & & Overweight & $9(22.5)$ & $8(21.6)$ & & \\
\hline & & Obese & $1(2.5)$ & $2(5.4)$ & & \\
\hline & Perceived economic & Very low & $3(7.5)$ & $4(10.8)$ & 4.22 & .239 \\
\hline & status & Low & $12(30.0)$ & 7 (18.9) & & \\
\hline & & Average & $24(60.0)$ & $21(56.8)$ & & \\
\hline & & High & $1(2.5)$ & $5(13.5)$ & & \\
\hline \multirow{10}{*}{$\begin{array}{c}\text { Children's } \\
\text { outcome } \\
\text { variables }\end{array}$} & BMI $\left(\mathrm{kg} / \mathrm{m}^{2}\right)$ & & $17.91 \pm 3.03$ & $19.18 \pm 3.38$ & 1.75 & .085 \\
\hline & Physical strength & Flexibility $(\mathrm{cm})$ & $6.98 \pm 6.82$ & $8.26 \pm 6.28$ & 0.85 & .397 \\
\hline & evaluation & Muscular endurance (reps/min) & $36.60 \pm 26.20$ & $36.86 \pm 16.30$ & 0.53 & .958 \\
\hline & & Agility (cm) & $119.39 \pm 25.63$ & $124.02 \pm 21.52$ & 0.85 & .396 \\
\hline & Nutritional assessment & Fruit intake & $3.70 \pm 1.76$ & $4.01 \pm 1.73$ & 0.89 & .376 \\
\hline & (days/week) & Vegetable intake & $5.16 \pm 1.57$ & $4.73 \pm 1.48$ & 1.28 & .205 \\
\hline & & Dairy intake & $4.10 \pm 1.74$ & $4.43 \pm 1.64$ & 0.86 & .392 \\
\hline & Nutritional knowledge & & $62.00 \pm 25.14$ & $71.35 \pm 19.17$ & 1.82 & .072 \\
\hline & Body image satisfaction & & $89.10 \pm 16.24$ & $93.38 \pm 12.54$ & 1.29 & .202 \\
\hline & Self-esteem & & $75.03 \pm 6.42$ & $75.11 \pm 12.38$ & 0.04 & .971 \\
\hline
\end{tabular}

BMI, body mass index; reps, repetitions. 
Table 3. Effects of Combined Obesity Prevention Program Including Primary Caregiver $(N=77)$

\begin{tabular}{|c|c|c|c|c|c|c|}
\hline \multirow[t]{2}{*}{ Variables } & \multirow[t]{2}{*}{ Group } & Pretest & Posttest & $\begin{array}{c}\text { Posttest after } \\
4 \text { weeks }\end{array}$ & \multirow[t]{2}{*}{ Source } & \multirow[t]{2}{*}{$\mathrm{F}(p)$} \\
\hline & & $\mathrm{M} \pm \mathrm{SD}$ & $\mathrm{M} \pm \mathrm{SD}$ & $\mathrm{M} \pm \mathrm{SD}$ & & \\
\hline \multirow[t]{2}{*}{ BMI $\left(\mathrm{kg} / \mathrm{m}^{2}\right)$} & Int. $(n=40)$ & $17.91 \pm 3.03$ & $18.02 \pm 3.06$ & $18.13 \pm 2.98$ & G & $3.56(.063)$ \\
\hline & Cont. $(n=37)$ & $19.18 \pm 3.38$ & $19.40 \pm 3.27$ & $19.55 \pm 3.30$ & $\begin{array}{c}\mathrm{T} \\
\mathrm{G}^{*} \mathrm{~T}\end{array}$ & $\begin{array}{c}16.50(<.001) \\
1.11(.318)\end{array}$ \\
\hline \multicolumn{7}{|c|}{ Physical strength evaluation } \\
\hline \multirow{2}{*}{ Flexibility (cm) } & Int. $(n=40)$ & $6.98 \pm 6.82$ & $7.49 \pm 6.44$ & $8.61 \pm 5.90$ & G & $0.11(.739)$ \\
\hline & Cont. $(n=37)$ & $8.26 \pm 6.28$ & $8.38 \pm 6.36$ & $7.85 \pm 6.72$ & $\begin{array}{c}\mathrm{T} \\
\mathrm{G}^{*} \mathrm{~T}\end{array}$ & $\begin{array}{l}1.47(.235) \\
4.64(.020)\end{array}$ \\
\hline \multirow{2}{*}{$\begin{array}{l}\text { Muscular endurance } \\
\text { (reps/min) }\end{array}$} & Int. $(n=40)$ & $36.60 \pm 26.20$ & $50.43 \pm 31.68$ & $54.78 \pm 30.91$ & G & $3.09(.083)$ \\
\hline & Cont. $(n=37)$ & $36.86 \pm 16.30$ & $39.32 \pm 21.43$ & $37.19 \pm 21.84$ & $\begin{array}{c}\mathrm{T} \\
\mathrm{G}^{*} \mathrm{~T}\end{array}$ & $\begin{array}{l}14.02(<.001) \\
11.22(<.001)\end{array}$ \\
\hline \multirow[t]{3}{*}{ Agility (cm) } & Int. $(n=40)$ & $119.39 \pm 25.63$ & $118.03 \pm 26.50$ & $119.52 \pm 26.96$ & G & $1.33(.253)$ \\
\hline & Cont. $(n=37)$ & $124.02 \pm 21.52$ & $128.51 \pm 20.11$ & $128.99 \pm 27.33$ & $\mathrm{~T}$ & $0.90(.383)$ \\
\hline & & & & & $\mathrm{G}^{*} \mathrm{~T}$ & $2.84(.078)$ \\
\hline \multicolumn{7}{|c|}{ Nutritional assessment (days/week) } \\
\hline \multirow[t]{3}{*}{ Fruit intake } & Int. $(n=40)$ & $3.70 \pm 1.76$ & $4.03 \pm 1.85$ & $4.33 \pm 1.64$ & G & $0.27(.605)$ \\
\hline & Cont. $(n=37)$ & $4.01 \pm 1.73$ & $4.11 \pm 1.71$ & $4.27 \pm 1.52$ & $\mathrm{~T}$ & $1.30(.276)$ \\
\hline & & & & & $\mathrm{G}^{*} \mathrm{~T}$ & $0.32(.730)$ \\
\hline \multirow[t]{3}{*}{ Vegetable intake } & Int. $(n=40)$ & $5.16 \pm 1.57$ & $4.70 \pm 1.83$ & $4.90 \pm 1.61$ & G & $1.30(.258)$ \\
\hline & Cont. $(n=37)$ & $4.73 \pm 1.48$ & $4.49 \pm 1.71$ & $4.46 \pm 1.52$ & $\mathrm{~T}$ & $2.73(.081)$ \\
\hline & & & & & $\mathrm{G}^{*} \mathrm{~T}$ & $0.34(.664)$ \\
\hline \multirow{3}{*}{ Dairy intake } & Int. $(n=40)$ & $4.10 \pm 1.74$ & $4.25 \pm 1.97$ & $4.68 \pm 1.77$ & G & $5.10(.013)$ \\
\hline & Cont. $(n=37)$ & $4.43 \pm 1.64$ & $4.86 \pm 1.62$ & $5.22 \pm 1.44$ & $\mathrm{~T}$ & $5.05(.013)$ \\
\hline & & & & & $\mathrm{G}^{*} \mathrm{~T}$ & $0.24(.734)$ \\
\hline \multirow[t]{3}{*}{ Nutritional knowledge } & Int. $(n=40)$ & $62.00 \pm 25.14$ & $84.00 \pm 19.85$ & $85.00 \pm 21.60$ & G & $0.08(.781)$ \\
\hline & Cont. $(n=37)$ & $71.35 \pm 19.17$ & $75.68 \pm 23.16$ & $87.03 \pm 20.12$ & $\mathrm{~T}$ & $23.69(<.001)$ \\
\hline & & & & & $\mathrm{G}^{*} \mathrm{~T}$ & $4.79(.010)$ \\
\hline \multirow[t]{3}{*}{ Body image satisfaction } & Int. $(n=40)$ & $89.10 \pm 16.24$ & $100.95 \pm 14.08$ & $103.25 \pm 14.05$ & G & $0.05(.825)$ \\
\hline & Cont. $(n=37)$ & $93.38 \pm 12.54$ & $100.57 \pm 16.03$ & $97.49 \pm 15.56$ & $\mathrm{~T}$ & $21.76(<.001)$ \\
\hline & & & & & $\mathrm{G}^{*} \mathrm{~T}$ & $4.74(.012)$ \\
\hline \multirow[t]{2}{*}{ Self-esteem } & Int. $(n=40)$ & $75.03 \pm 6.42$ & $87.03 \pm 9.19$ & $92.63 \pm 12.79$ & G & $5.35(.023)$ \\
\hline & Cont. $(\mathrm{n}=37)$ & $75.11 \pm 12.38$ & $79.89 \pm 14.33$ & $85.92 \pm 12.10$ & $\begin{array}{c}\mathrm{T} \\
\mathrm{G}^{*} \mathrm{~T}\end{array}$ & $\begin{array}{c}47.37(<.001) \\
3.81(.029)\end{array}$ \\
\hline
\end{tabular}

\begin{tabular}{|c|c|c|c|c|c|}
\hline \multirow{2}{*}{ Variables } & \multirow{2}{*}{ Group } & \multicolumn{2}{|c|}{ Posttest-Pretest } & \multicolumn{2}{|c|}{ Posttest after 4 weeks-Pretest } \\
\hline & & $\mathrm{M} \pm \mathrm{SD}$ & $t(p)$ & $\mathrm{M} \pm \mathrm{SD}$ & $\mathrm{t}(p)$ \\
\hline \multirow[t]{2}{*}{ Flexibility $(\mathrm{cm})$} & Int. $(n=40)$ & $0.51 \pm 2.36$ & \multirow[t]{2}{*}{$0.78(.441)$} & $1.63 \pm 4.31$ & \multirow[t]{2}{*}{$2.34(.022)$} \\
\hline & Cont. $(n=37)$ & $0.13 \pm 1.87$ & & $-0.41 \pm 3.23$ & \\
\hline \multirow{2}{*}{$\begin{array}{l}\text { Muscular endurance } \\
\text { (reps/min) }\end{array}$} & Int. $(n=40)$ & $13.83 \pm 17.99$ & \multirow[t]{2}{*}{$3.23(.002)$} & $18.18 \pm 22.68$ & \multirow[t]{2}{*}{$4.03(<.001)$} \\
\hline & Cont. $(n=37)$ & $2.46 \pm 12.01$ & & $0.32 \pm 15.84$ & \\
\hline \multirow[t]{2}{*}{ Nutritional knowledge } & Int. $(n=40)$ & $22.00 \pm 27.85$ & \multirow[t]{2}{*}{$3.31(.001)$} & $23.00 \pm 31.88$ & \multirow[t]{2}{*}{$1.23(.225)$} \\
\hline & Cont. $(n=37)$ & $4.32 \pm 18.34$ & & $15.68 \pm 19.51$ & \\
\hline \multirow{2}{*}{ Body image satisfaction } & Int. $(n=40)$ & $11.85 \pm 12.39$ & \multirow[t]{2}{*}{$1.64(.105)$} & $14.15 \pm 16.33$ & \multirow[t]{2}{*}{$2.71(.008)$} \\
\hline & Cont. $(n=37)$ & $7.19 \pm 12.50$ & & $4.11 \pm 16.21$ & \\
\hline \multirow[t]{2}{*}{ Self-esteem } & Int. $(n=40)$ & $12.00 \pm 10.68$ & \multirow[t]{2}{*}{$2.84(.006)$} & $17.60 \pm 14.04$ & \multirow[t]{2}{*}{$2.01(.048)$} \\
\hline & Cont. $(n=37)$ & $4.78 \pm 11.59$ & & $10.81 \pm 15.56$ & \\
\hline
\end{tabular}

BMI, body mass index; Cont., control group; G, group; Int., intervention group; reps, repetitions; $\mathrm{T}$, time. 
(A)

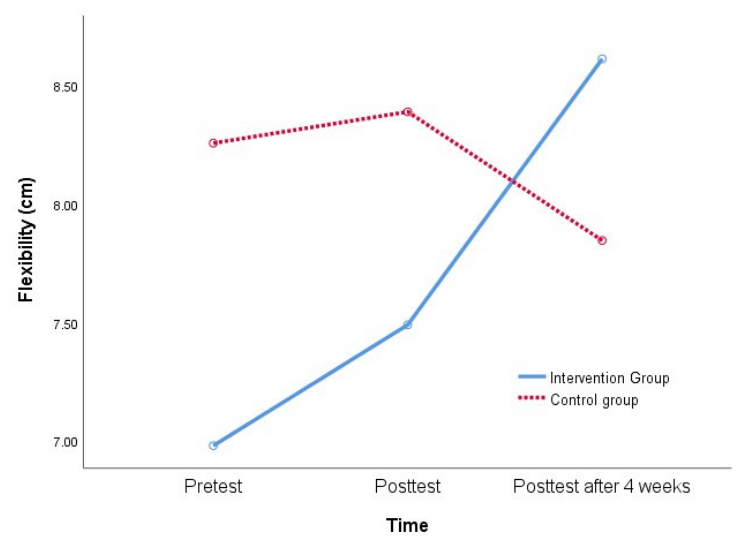

(C)

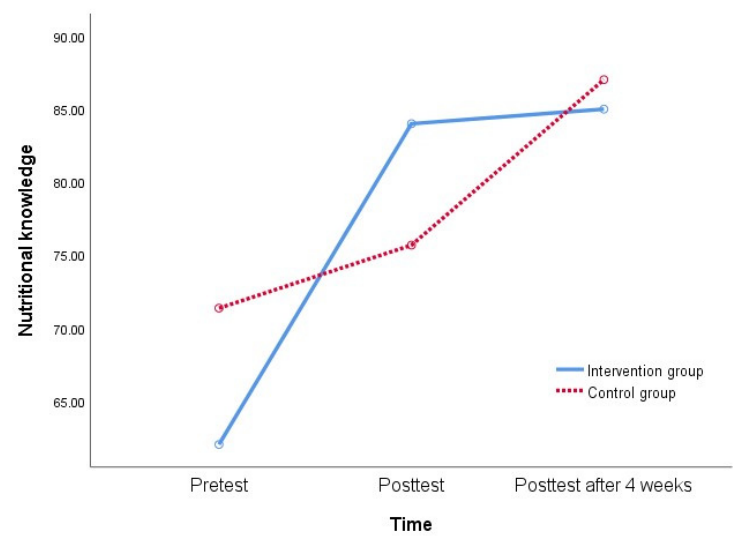

(B)

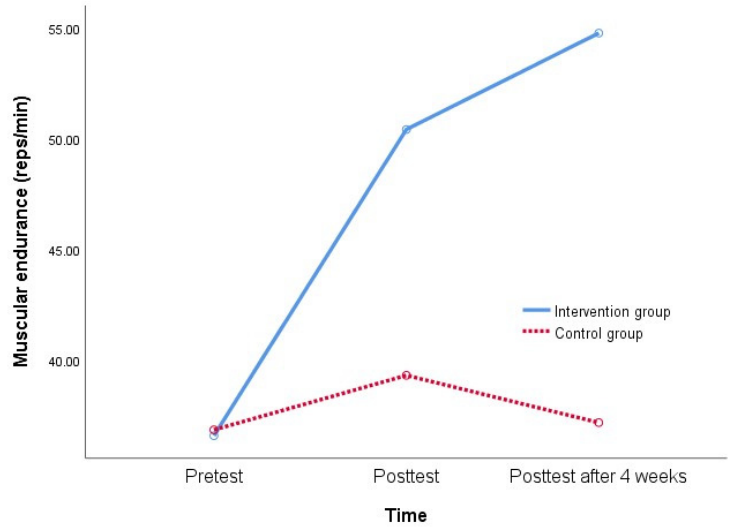

(D)

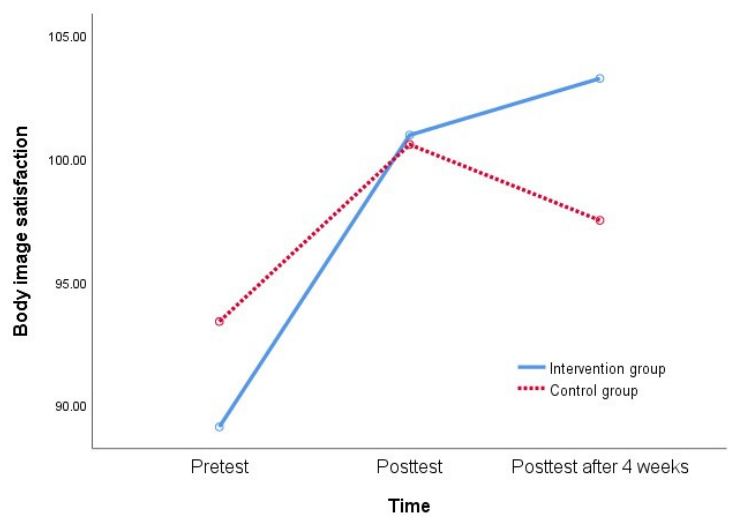

(E)

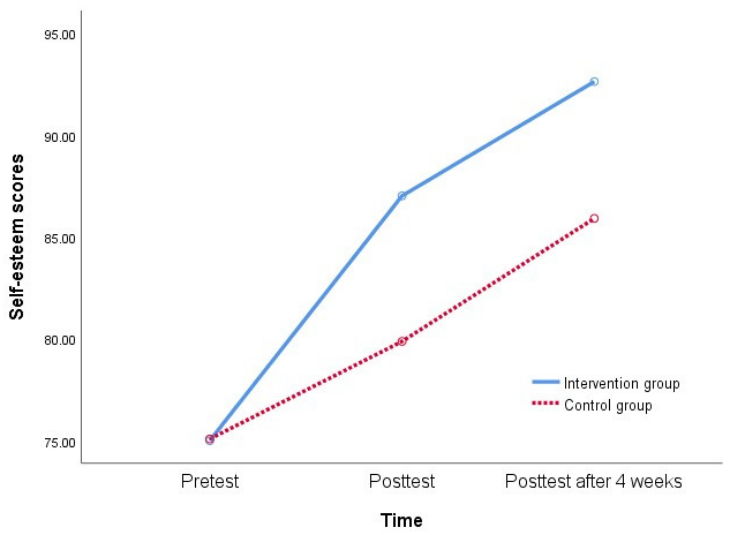

Figure 2. Effects on the outcome variables over time in both groups, based on the repeated-measures analysis. (A) Flexibility. (B) Muscular endurance. (C) Nutritional knowledge. (D) Body image satisfaction. (E) Self-esteem. reps, repetitions.

and time $(\mathrm{F}=4.79, p=.010)$. There was no significant difference between the groups $(\mathrm{F}=0.08, p=.781)$. Therefore, hypothesis 4 was supported. The nutritional knowledge of the intervention group increased by $22.00 \pm 27.85$ points immediately after the intervention $(\mathrm{t}=3.31, p=.001)$ (Figure 2-C, Table 3).

\section{5) Hypothesis 5}

With regard to the body image satisfaction scores of chil- 
dren, there was no statistically significant difference between the groups ( $\mathrm{F}=0.05, p=.825)$. However, there were statistically significant differences across the time points $(\mathrm{F}=21.76, p<$ $.001)$ and an interaction between group and time ( $\mathrm{F}=4.74$, $p=.012$ ). Therefore, hypothesis 5 was supported. Four weeks after the intervention, the mean body image satisfaction score of the intervention group increased by $14.15 \pm 16.33$ points $(\mathrm{t}=2.71, p=.008)$ (Figure 2-D, Table 3).

\section{6) Hypothesis 6}

Regarding the self-esteem scores of the children, there were statistically significant differences between the groups ( $\mathrm{F}=5.35$, $p=.023)$, differences across the time points $(\mathrm{F}=47.37, p<.001)$, and an interaction between group and time $(\mathrm{F}=3.81, p=.029)$. Therefore, hypothesis 6 was supported. Immediately after the intervention, the average self-esteem score of the intervention group increased by $12.00 \pm 10.68$ points ( $t=2.84, p=.006$ ). Four weeks after the intervention, the average self-esteem score of the intervention group increased by $17.60 \pm 14.04$ points $(t=$ 2.01, $p=.048$ ) (Figure 2-E, Table 3).

\section{DISCUSSION}

We found that this program was effective at improving the children's flexibility and muscle endurance in terms of the physical activity component. Since obesity control should combine anaerobic and aerobic exercise, the program implemented in this study combined muscle strengthening exercises with boxing to balance the physical activities of the children. As a result, the program confirmed the lasting effects of enhanced muscular endurance. While aerobic exercise is good for range of motion, continued muscle exercise improves muscle potential [21]. The program was determined to have no effect on agility, as agility tends to be affected by learning through experience [22].

The effects of the combined exercises performed by the children were not clear. In Europe, combined exercise, which includes muscle strength training, improved the muscle strength of obese children aged 6-18 years [21]. A meta-analysis of the effects of combined exercise on obese adolescents in Korea also found that combined exercise helped improve muscular endurance [23]. World Health Organization guidelines for children's physical activities also recommend muscle-strengthening activities, as well as aerobic activities, for children [24]. However, a recent study found that aerobic exercise alone showed similar effects on overweight and obese children aged 12 to 17 years old to combined exercise [25]. While studies have repeatedly found that providing a combined exercise program that includes both anaerobic and aerobic exercise is effective for obesity control in adults, the effects of combined intervention programs on children remain unclear [25]. In the future, it will be necessary to verify the effects of combined exercise across multiple studies by observing its effects on children according to numerous different variables in diverse environments.

Considering that interventions experienced in person by students are more effective than didactic nutrition education, we designed a practical program (cooking class) for the following week based on the educational contents of the previous week. In addition, since the children's home and living environments had a great effect on their eating behavior [5], we gave pamphlets to primary caregivers or gave them time to cook together with their children. The program was developed so that children could be taught individual nutritional knowledge with which to cultivate healthy eating habits, and parents were also taught nutritional knowledge so they could provide healthy meals for their children with proper encouragement and guidance. As a result, however, although the nutritional knowledge of the children improved, actual behaviors did not change, and no increases were observed with regard to children's intake of fruits, vegetables, and dairy. This is likely because the interventions aimed at primary caregivers, such as only providing a nutritional pamphlet, were somewhat passive. Parents with a high level of nutritional knowledge have been found to be more likely to influence their children to consume high-fiber foods, low-fat foods, vegetables, and fruits and maintain an overall healthy diet [11]. Thus, more specific interventions to enhance parents' nutritional knowledge should be explored.

Moreover, given that there were no significant differences in fruit, vegetable, and dairy intake, we found that actual eating habits are hard to improve through education and nutritional knowledge alone. The best method for influencing children's actual eating behaviors is to ensure that their surrounding environment provides them access to free fruits or vegetables [26]. Since children from low-income families have limited access to quality foods, programs that provide fruits and vegetables directly to low-income families are gaining increased attention. Ridberg et al. [27] found that children's consumption of vegetables and fruits improved after implementing a program that directly provided tokens and coupons for purchasing fruits and vegetables to children from low-income households. In addition, in-person participation in gardening and cooking programs for children can help them to gain knowledge about ingredients and help them maintain healthy eating habits over the long term [26]. When providing nutrition education in CCCs, in-person, participatory programs for children should be developed rather than straightforward nutrition education.

This study found that the program improved children's 
body image satisfaction four weeks after the end of the intervention. Body image is a feeling and attitude toward one's body. If a child has a positive body image, it decreases their level of stress when participating in physical activities [28]. According to prior studies, participation in exercise positively affects children's body image [29]. Since body image is an important factor for influencing eating behaviors and habits related to physical activity, children should spend time in environments that enhance their body image. In addition, schoolaged children experience rapid physical and physiological developments and develop a growing interest in their bodies [10]. Therefore, it is necessary to provide obese children with an environment in which they can cultivate a positive body image, since perceived body image in this period is an important factor for the formation of eating behaviors and habits regarding physical activity. Therefore, future programs developed for obese children should include interventions that can provide them with a positive body image.

We confirmed that our program improved children's selfesteem after the intervention, which is a similar finding to that of Lee and Oh [29], who conducted a 26-week obesity control program for children. Lowry et al. [30] also observed positive changes with regard to self-esteem when families were involved in weight management programs for children in their review of 21 articles. Children's self-esteem improved as a result of acquiring self-control and cultivating better habits through the behavior modification component of the program from this study. Since obesity has diverse effects on children's psycho-social development, mental health problems caused by obesity should be taken as seriously as physical health [8]. Low-income families may not have the means to protect and educate their children at home after school due to parents' absence or economic status [3]. As a result, children from low-income families are often neglected or ignored and thus are socially and psychologically vulnerable. In this regard, psychosocial approaches to developing obesity management programs for children from low-income families should be considered.

Since the program did not specifically target obese children, a significant change in BMI was not observed. However, numerous variables related to children's obesity still showed improvements as a result of the program. Since school-aged children are at an especially important period in their development during which their habits are in the process of being formed, efforts should be made to encourage children to adopt a healthy lifestyle and eating habits through routine health management. In addition, the factors that affect children's obesity are diverse and include physical, psychological, mental, and environmental components. Hence, controlling children's obesity requires a multidisciplinary approach in- volving experts in various areas $[7,8,10]$. Since this program included groups of experts in physical education, nutrition, nursing, and social welfare, similar programs could provide a professional and systematic solution to addressing obesity in children. A multidisciplinary approach is also needed for controlling childhood obesity in the future.

Children from low-income families have limited access to programs that promote physical activity due to economic difficulties [3]. As a result, prior studies have found that children from low-income families typically ate heavy dinners and watched TV for longer periods of time than children from middle and high-income families $[3,5]$. As such, it may be difficult to provide children from low-income families with a stable environment in which to promote physical activities in the home. Thus, CCCs, where many children from low-income families spend much of their time, should offer programs to children from low-income families to promote regular physical activity.

This study successfully encouraged children to monitor their daily living habits so that they could develop healthy lifestyles, set specific goals, and manage their eating habits, lifestyles, and weight loss. Although this study did not use computers or the internet, which children tend to prefer according to a study by Saelens et al. [20], it instead provided tailored interventions that included counseling with the children to set individualized goals. In addition, parents were informed of their children's goals and the contents of the program so that they could help to manage their children's goals in the home environment.

Behavioral modification systematically corrects people's diets, exercise habits, and other behaviors. While behavior modification therapy results in a lower weight loss rate than other obesity control methods, it has few side effects, a low rate of attrition, and is effective at helping people to maintain their weight loss [9]. Since school-aged children are in the process of forming various behaviors, a behavioral modification component should be included in obesity control programs to encourage school-aged children to cultivate healthy lifestyles and control obesity during adolescence and adulthood in the long term.

The primary caregiver participation component inspired parents to become more interested in their children's behaviors by encouraging them to pay closer attention to their children's eating and exercise habits [1]. Parents also tended to be more careful about their own eating and exercise habits as a result of the program. Since the family environment is a crucial factor for influencing children's formation of habits through behavioral modeling, parental involvement is essential for obesity control in the future [5]. In addition, community-based programs that include a participatory element for 
primary caregivers are essential and have been found to have a significant effect on children under the age of 13 years old $[7,8]$. Primary caregivers from low-income families tend to be diverse in terms of age and occupation, so many may find it difficult to participate in programs due to economic constraints. Therefore, efforts should be taken to enable primary caregivers from low-income families to actively participate in children's obesity management programs.

Although primary care providers participated in the program in this study, the variables related to primary care providers were not measured. In the future, variables such as the number of fruits, vegetables, and dairy products consumed by the children should be confirmed by primary caregivers for accuracy and to verify the effectiveness of the program. While our program strengthened the connection between children, their homes, and a local CCC, it still did not incorporate learning in schools, where children spend most of their time. In the future, children's health management will show improvement if they are supported in their home environments, schools, and CCCs and if programs include the cooperation of school health teachers and homeroom teachers. In addition, since our program was conducted for a short period (only 8 weeks), and since most programs for obese children in Korea are 12 weeks long [10], it may be necessary to extend the duration of the program in the future to verify longer-term effects through further research.

\section{CONCLUSION}

This study examined the effects of a program that incorporated physical activity, nutrition education, behavioral modification, and primary caregiver participation components to prevent obesity in children from low-income families. As a result, we found that children's flexibility, muscle endurance, nutritional knowledge, body image satisfaction, and self-esteem improved. Composite interventions should be routinely offered in the future, and interventions should be developed that include participation by children's primary caregivers. In addition, programs should be developed for children from low-income families that consider psychological factors. Based on the results of this study, we recommend that further comparative studies be conducted that extend the length of the program to identify long-term educational effects. It is also necessary to use various indicators to confirm the effectiveness of the program.

\section{ORCID}

Namhee Park https://orcid.org/0000-0002-9693-5921

Mihae Im https://orcid.org/0000-0002-3795-5201

\section{Authors' contribution}

Conceptualization: all authors; Data collection: Namhee Park; Formal analysis: Mihae Im; Writing-original draft, Writing-review and editing: all authors; Final approval of published version: all authors.

\section{Conflict of interest}

No existing or potential conflict of interest relevant to this article was reported.

\section{Funding}

This study was supported by the 'Health Specialization Project' funded by Busan Metropolitan City and the Korea Health Promotion Institute in 2018.

\section{Data availability}

Please contact the corresponding author for data availability.

\section{Acknowledgements}

We would like to give special thanks for financial support from the 'Health Specialization Project' funded by Busan Metropolitan City and the Korean Health Promotion Development Institute.

\section{REFERENCES}

1. Ogden CL, Carroll MD, Fakhouri TH, Hales CM, Fryar CD, Li X, et al. Prevalence of obesity among youths by household income and education level of head of household-United States 2011-2014. Morbidity and Mortality Weekly Report. 2018;67(6):186-189. https://doi.org/10.15585/mmwr.mm6706a3

2. Son JY, Kwon SW. A study on the intervention plan for the mitigation of health inequality in children. Research Report. Seoul: Childfund; 2014 December. Report No.: 2014-11.

3. Lee J, Park J, Kim HS, Kim WS, Hwang G. Barriers to promoting physical activity among overweight and obese children from low-income families using community child care centers. Journal of Korean Public Health Nursing. 2017;31(2):327-340. https://doi.org/10.5932/JKPHN.2017.31.2.327

4. Sapkota T, Houkes I, Bosma H. Vicious cycle of chronic disease and poverty: A qualitative study in present day Nepal. International Health. 2021;13(1):30-38. https://doi.org/10.1093/inthealth/ihaa016

5. Kim HS, Park J, Ma Y, Im M. What are the barriers at home and school to healthy eating?: Overweight/obese child and parent 
perspectives. Journal of Nursing Research. 2019;27(5):e48. https://doi.org/10.1097/jnr.0000000000000321

6. Sung KS, Yoon YM, Kim EJ. Meta-analysis of the effects of obesity management program for children. Child Health Nursing Research. 2013;19(4):262-269.

https://doi.org/10.4094/chnr.2013.19.4.262

7. Feng L, Wei DM, Lin ST, Maddison R, Mhurchu CN, Jiang Y, et al. Systematic review and meta-analysis of school-based obesity interventions in Mainland China. PLoS One. 2017;12(9):e0184704. https://doi.org/10.1371/journal.pone.0184704

8. Bleich SN, Segal J, Wu Y, Wilson R, Wang Y. Systematic review of community-based childhood obesity prevention studies. Pediatrics. 2013;132(1):e201-e210. https:// doi.org/10.1542/peds.2013-0886

9. Kelley CP, Sbrocco G, Sbrocco T. Behavioral modification for the management of obesity. Primary Care. 2016;43(1):159-175. https://doi.org/10.1016/j.pop.2015.10.004

10. Park J, Ma H, Lee Y, Oh H. Trends in intervention study for childhood obesity in Korea. Child Health Nursing Research. 2017;23(1): 81-90. https://doi.org/10.4094/chnr.2017.23.1.81

11. Yabancı N, Kısaç İ, Karakuş SŞ. The effects of mother's nutritional knowledge on attitudes and behaviors of children about nutrition. Procedia-Social and Behavioral Sciences. 2014;116(21):4477-4481. https://doi.org/10.1016/j.sbspro.2014.01.970

12. Kim HS, Park J, Park K, Lee MN, Ham OK. Parent involvement intervention in developing weight management skills for both parents and overweight/obese children. Asian Nursing Research. 2016;10(1):11-17. https://doi.org/10.1016/j.anr.2015.07.006

13. Ministry of Health and Welfare. National community child care center statistical survey. Research Report. Sejong: Ministry of Health and Welfare; 2016 December. Report No.: 11-135200- 002034-10.

14. Seoul National University Institute of Sport Science. Physical activity promotion system [Internet]. Sejong: Ministry of Education; 2009 [cited 2021 March 8]. Available from:

https://www.moe.go.kr/boardCnts/view.do?boardID=316\&lev= $0 \&$ statusYN=C\&s=moe\&m $=0302 \&$ opType $=$ N\&boardSeq $=14508$

15. Korea Health Promotion Foundation. 4th Health Plan 2020, 20162020 [Internet]. Seoul: Ministry of Health and Welfare; 2015 [cited 2021 March 8]. Available from:

https://khealth.or.kr/board/view?pageNum=1\&rowCnt=10\& menuId=MENU00829\&maxIndex=99999999999999\&minIndex= 99999999999999\&schType=0\&schText=\&categoryId=\&continent $=\&$ country $=\& u p D o w n=0 \&$ boardStyle $=\&$ no $1=0 \& \operatorname{linkId}=559210$

16. Franzoi SL, Shields SA. The body-esteem scale: Multidimensional structure and sex differences in a college population. Journal of Personality Assessment. 1984;48(2):173-178. https://doi.org/10.1207/s15327752jpa4802_12

17. Shin KH. The difference self-esteem and academic achievement according to children's body-esteem [master's thesis]. Chungcheongbuk-do: The Korea National University of Education, Chung-Buk; 1996. p. 1-68
18. Harter S. The perceived competence scale for children. Child Development. 1982;53(1):87-97. https://doi.org/10.2307/1129640

19. Lee $Y$, So $H$. The determinants affecting the health behavior of middle school student. Chungnam Medical Journal. 1996;23(1):75-86.

20. Saelens BE, Sallis JF, Wilfley DE, Patrick K, Cella JA, Buchta R. Behavioral weight control for overweight adolescents initiated in primary care. Obesity Research. 2002;10(1):22-32.

https://doi.org/10.1038/oby.2002.4

21. Thivel D, Ring-Dimitriou S, Weghuber D, Frelut ML, O'Malley G. Muscle strength and fitness in pediatric obesity: A systematic review from the European childhood obesity group. Obesity Facts. 2016;9(1):52-63. https://doi.org/10.1159/000443687

22. Azmi K, Kusnanik NW. Effect of exercise program speed, agility, and quickness (SAQ) in improving speed, agility, and acceleration. Journal of Physics: Conference Series. 2018;947(1):012043. https://doi.org/10.1088/1742-6596/947/1/012043

23. Kim YW, Cheon SM. Meta-analysis of the effects of combined exercise on fitness and body composition in obese adolescents. Journal of Sport and Leisure Studies. 2016;66:701-713.

https://doi.org/10.51979/KSSLS.2016.11.66.701

24. World Health Organization. Physical activity and young people [Internet]. Switzerland: World Health Organization; 2021 [cited 2021 March 8]. Available from:

https://www.who.int/ncds/prevention/physical-activity/factsh eet_young_people/en/

25. Lee S, Libman I, Hughan K, Kuk JL, Jeong JH, Zhang D, et al. Effects of exercise modality on insulin resistance and ectopic fat in adolescents with overweight and obesity: A randomized clinical trial. Journal of Pediatrics. 2019;206:91-98.

https://doi.org/10.1016/j.jpeds.2018.10.059

26. DeCosta P, Møller P, Frøst MB, Olsen A. Changing children's eating behavior-A review of experimental research. Appetite. 2017; 113(1):327-357. https://doi.org/10.1016/j.appet.2017.03.004

27. Ridberg RA, Bell JF, Merritt KE, Harris DM, Young HM, Tancredi DJ. Effect of a fruit and vegetable prescription program on children's fruit and vegetable consumption. Preventing Chronic Disease. 2019;16:E73. https://doi.org/10.5888/pcd16.180555

28. Voelker DK, Reel JJ, Greenleaf C. Weight status and body image perceptions in adolescents: Current perspectives. Adolescent Health, Medicine and Therapeutics. 2015;6:149-158.

https://doi.org/10.2147/AHMT.S68344

29. Lee JH, Oh S. Effects of the 26-weeks obesity management program on obesity index, self-esteem, self-efficacy, and body image among obese elementary school children. Journal of the Korea Academia-Industrial cooperation Society. 2016;17(9):83-93. https://doi.org/10.5762/KAIS.2016.17.9.83

30. Lowry KW, Sallinene BJ, Janicke DM. The effects of weight management programs on self-esteem in pediatric overweight populations. Journal of Pediatric Psychology. 2007;32(10):1179-1195. https://doi.org/10.1093/jpepsy/jsm048 